\title{
Coronavirus Disease-19 and Liver Injury
}

\author{
Gontar Alamsyah Siregar ${ }^{1}$, Ginanda Putra Siregar ${ }^{2}$, Darmadi Darmadi ${ }^{1 *}$, Riska Habriel Ruslie ${ }^{3}$ \\ ${ }^{1}$ Department of Internal Medicine, Division of Gastroenterohepatology, Faculty of Medicine, Universitas Sumatera Utara, \\ Medan, Indonesia; ${ }^{2}$ Department of Surgery, Faculty of Medicine, Universitas Sumatera Utara, Medan, Indonesia; ${ }^{3}$ Department \\ of Child Health, Faculty of Medicine, Universitas Prima Indonesia, Medan, Indonesia
}

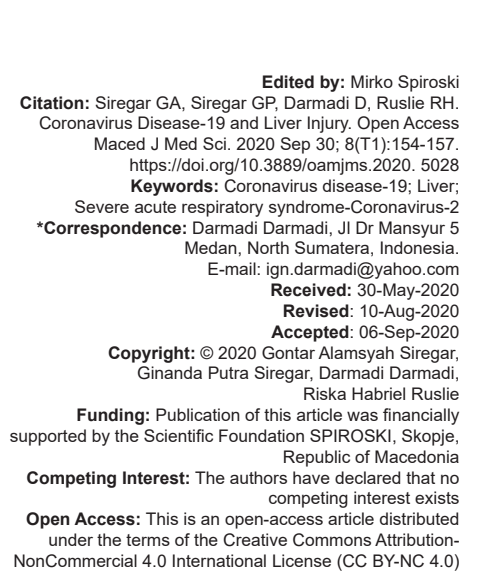

Introduction

Pneumonia due to unknown etiology was found in Wuhan, Hubei Province, China in December 2019 [1], [2], [3]. Huanan seafood market was suspected as the starting area of the spreading. A virus, namely, 2019 novel coronavirus (CoV) was identified as the etiology of the disease in January 7 , 2020. In February 11, 2020, International Committee on Taxonomy of Viruses renamed $2019 \mathrm{nCoV}$ as severe acute respiratory syndrome-CoV-2 (SARS-CoV-2). Later, World Health Association (WHO) announced the disease caused by SARS-CoV-2 infection as CoV disease-(COVID-19) [1], [4]. In March 11, 2020, the WHO announced COVID-19 as a pandemic [3], [5], [6], [7].

$\mathrm{CoV}$ is an enveloped, single-stranded positivesense RNA virus [1], [7], [8]. Its Alpha and Beta generas commonly infect mammals while Gamma and Delta infect birds. SARS-CoV-2 itself is belonged to BetaCoV genus and Coronaviridae family [1], [5], [7], [9]. Previously, two CoVs had caused epidemics. The first was SARS-CoV in Guangdong, China in November 2002 and the second was Middle East respiratory syndrome CoV (MERS-CoV) in Saudi Arabia in 2012 [1], [3], [10]. The first epidemic caused 774 deaths while the second caused 858 [1]. The mortality rate from SARS-CoV-2 is lower compared to SARS and MERS [9], [10].

\section{Epidemiology}

Median age of patients with COVID-19 is between 41 and 57 years. Male is dominant compared to female [1], [11]. Even though, there are several studies reporting comparable proportion of patients based on gender [2], [4]. About 25.2-50.5\% patients have comorbidities such as hypertension, diabetes, chronic obstructive pulmonary disease, cardiovascular disease, and malignancy [1]. About $10.8 \%$ patients have pre-existing liver disease [12]. The mortality of COVID-19 ranges from $0 \%$ to $14.6 \%$ [1]. The most common death-leading complication is acute respiratory distress syndrome [10]. Factors contributing to higher risk of mortality are older age, underlying comorbidities, and disease severity based on clinical findings and auxiliary examinations [11], [13]. At the time of writing, there are 5,491,678 cases of COVID-19 with total deaths of 349,190 cases. The most prevalent region is America, followed by Europe [14]. The incidence of 
liver injury due to COVID-19 was varied between $14.8 \%$ and $78 \%$ [3], [9]. Other literatures stated that liver injury is observed in $60 \%$ patients with COVID-19 [8], [15]. Cai et al. found a similar rate of liver injury which was $76.3 \%$ of total patients with COVID-19 and $21.5 \%$ of all patients on admission [5].

\section{Pathophysiology}

Bats are the natural reservoir of SARS-CoV-2 and the virus spreads to human through pangolins as one of the intermediate hosts [1]. The virus may be isolated from pangolins, especially Malayan pangolins. However, genomic sequence of SARS-CoV-2 in human is different from the wild virus, suggesting that mutation may have been occurred which allows human-to-human transmission [13]. Human-to-human transmission occurs through respiratory droplets directly or indirectly [4]. Fecal-oral transmission must also be wary of since viable SARS-CoV-2 can be isolated from patient's fecal sample [16]. SARS-CoV-2 infection is initiated by binding of spike glycoprotein to angiotensin converting enzyme 2 (ACE2). This process is followed by cell membrane fusion [11], [15], [17]. Viral RNA then integrates into host cell DNA. This process initiates viral protein synthesis and assembly of new viruses which readily infect other cells and damaging the cell [15], [18]. The affinity of SARS-CoV-2 to ACE2 is stronger compared to SARS-CoV [12], [13].

Literatures stated that ACE2 is highly expressed in cholangiocytes but only slightly in hepatocytes. As we know that bile duct epithelial cells play an important role in liver regeneration and immune response, it raises possibility that SARS-CoV-2 may directly invade those cells and cause liver function dysregulation [15], [16], [19], [20]. Furthermore, virusinduced cytopathic effects may directly cause liver damage [3]. Inflammation process, which is known as cytokine storm, also played an important role in damaging the liver of patients with critical condition due to COVID-19 [4], [6], [9], [11]. Lymphocytes are important in balancing immune response and preventing cytokine storm. Lymphopenia in COVID-19 patients leads to aggravation of inflammatory response. Lymphopenia and elevated C-reactive protein (CRP) level were associated with the severity of liver injury, confirming cytokine storm as one of the underlying mechanisms of liver injury [3], [11], [15]. Hypoxia and shock from COVID-19 may cause ischemia in body organs including liver. This is another hypothesized mechanism of liver injury in patients with COVID-19 [6], [11]

SARS-CoV-2 infection is also found to increase apoptotic activity of hepatocytes. The process is mediated by SARS-CoV-2-specific protein 7a through caspase-dependent pathway [9]. Increased positive end expiratory pressure may also cause hepatic congestion by increasing right atrial pressure and impending venous return [3], [15]. Drug-induced liver damage should also be put in mind since antiviruses and antibiotics may increase the workload of liver. Hydroxychloroquine is used as one of the treatment choices due to its effect in alleviating disease progression but, in the other hand, it may cause hepatic failure. In patients with underlying liver diseases, such as chronic hepatitis and non-alcoholic fatty liver, the above situation will surely even more impair the liver function [3], [4], [6], [9], [11], [15], [16], [17].

\section{Clinical Manifestations}

Clinical symptoms of COVID-19 range from mild to severe. A study reported that moderate clinical severity patients were dominant. Fever is the most common symptom, followed by cough, fatigue, myalgia, sputum production, and headache [1], [2], [3]. Gastrointestinal symptoms are quite common such as diarrheas, loss of appetite, nausea, and vomiting [1], [16]. Gastrointestinal symptoms are more frequent in SARS and MERS compared to COVID-19 [1]

Various degree of liver damage had been reported in COVID-19 patients marked by elevated total bilirubin, alanine aminotransferase (ALT), and aspartate aminotransferase (AST) levels [19]. A study by Fan et al. showed that $37.2 \%$ patients with COVID-19 have abnormal liver function on admission and had higher fever compared to those with normal liver function [4]. Autopsy result of deceased patients showed that $58-78 \%$ of COVID-19 patients suffer from liver injury [16]. Higher prevalence of liver injury is observed in males, patients with more severe disease course, older age, and patient who received lopinavir/ ritonavir [4], [16]. The use of lopinavir/ritonavir increases the risk of liver injury as high as 4 times compared to patients who do not receive those antivirals [5]. The severity of liver injury is associated with the severity of disease course [9], [15], [17]. Table 1 summarizes evidence regarding liver injury in patients with COVID-19.

Table 1: Evidences of liver injury in patients with COVID-19

\begin{tabular}{|c|c|c|}
\hline Authors & Subjects & Findings \\
\hline Fan et al. [4] & 148 & $\begin{array}{l}37.2 \% \text { subjects had abnormal liver function on admission } \\
\text { Patients with liver abnormality had higher fever, higher } \\
\text { procalcitonin and CRP levels, and longer hospital stays }\end{array}$ \\
\hline Cai et al. [5] & 417 & $\begin{array}{l}21.5 \% \text { subjects had abnormal liver function during } \\
\text { hospitalization } \\
\text { ALT, AST, total bilirubin, and GGT levels were elevated } \\
\text { more than } 3 \text { times the upper normal limit within } 2 \text { weeks of } \\
\text { hospitalization }\end{array}$ \\
\hline Huang et al. [10] & 41 & $\begin{array}{l}31 \% \text { subjects had abnormal liver function } \\
\text { Subjects admitted to ICU had higher AST level compared } \\
\text { to non-ICU }\end{array}$ \\
\hline Zhang et al. [21] & 82 & $78 \%$ non-survivor subjects had hepatic injury \\
\hline Huang et al. [22] & 36 & $\begin{array}{l}13.33 \% \text { subjects had abnormal ALT, } 58.06 \% \text { had abnormal } \\
\text { AST, and } 12.9 \% \text { had abnormal total bilirubin levels }\end{array}$ \\
\hline Chen et al. [23] & 99 & $\begin{array}{l}28 \% \text { subjects had elevated ALT, } 35 \% \text { had elevated AST, } \\
18 \% \text { had elevated total bilirubin, and } 98 \% \text { had low albumin } \\
\text { levels }\end{array}$ \\
\hline
\end{tabular}

glutamyl transferase, ICU: Intensive care unit. COVID: Coronavirus disease. 


\section{COVID-19 in Patients with Pre-existing Liver Disease}

COVID-19 patients with liver injury tend to develop severe pneumonia and have longer hospital stay [4], [5], [24]. Literature stated that patients with hepatitis B or $\mathrm{C}$ viral infection are more prone to suffer from severe hepatitis due to enhanced viral replication during COVID-19 course. On the other hand, patients with pre-existing live diseases such as non-alcoholic fatty liver disease and liver cirrhosis had higher risk to develop severe form of COVID-19. Liver transplantation should be conducted prudently since the virus can be transmitted through transplanted organ [3]. Subjects with chronic liver disease coexisting with COVID-19 tended to suffer from deterioration of liver disease. The deterioration was in line with increasing stage of liver disease, resulting in higher mortality in subjects with liver diseases compared to those without (hazard ratio 19.2) [25]. This finding is confirmed by a study by lavarone et al. They reported that the presence of COVID-19 deteriorates liver function and increases the mortality of subjects with underlying liver injury. The 30-day-mortality rate for subjects with COVID-19 and pre-existing liver cirrhosis was as high as $34 \%$. The mortality was influenced by severity of liver disease [26].

\section{Auxiliary Examinations}

The most common laboratory findings are lymphopenia, thrombocytopenia, and leukopenia. Other inflammatory markers such as CRP and interleukin-6 are also elevated [1]. Liver enzymes elevation is also observed [1], [3], [5], [9], [15], [16], [17]. ALT level rose in $16-35 \%$ patients while elevated AST was observed in $21 \%$ patients [19]. Feng et al. reported the elevation of AST level in 6.2-36.6\% patients with COVID-19 and elevation of AST level in 21.3-28.1\% patients [11]. Ridruejo and Soza found a lower rate of AST and ALT elevation which is between $16 \%$ and $35 \%$ [6]. Other markers for liver injury are also detected including elevated bilirubin level and decreased albumin level. Gamma-glutamyl transferase (GGT) might also be elevated [3],[5],[9],[15],[16],[17]. Intheotherhand, alkaline phosphatasedidnotraisesignificantly [4],[5],[11],[16],[19]. Chest computed tomography showed ground glass opacity, bilateral patchy shadows, and consolidation in subsegmental areas [1], [10], [27]. Reversetranscriptase polymerase chain reaction (RT-PCR) from nasopharyngeal swab is considered as gold standard for diagnosing COVID-19 [1]. Other specimens also showed positive result with bronchoalveolar lavage fluid held the highest positive rate $(93 \%)$, followed by sputum $(72 \%)$, nasal swabs $(63 \%)$, fibrobronchoscope brush biopsy (46\%), pharyngeal swab (32\%), feces (29\%), and blood (1\%) [28].

From percutaneous liver biopsy specimen of COVID-19 patients with elevated ALT, there was marked apoptosis activity in the liver tissue, ballooning of hepatocytes, and mild-to-moderate lobular infiltration of lymphocytes. RT-PCR showed evidence of SARS-CoV-2 genome in livertissue butnot in serum of patients [8], [9]. Viral particles could not been identified by electron microscopy or histopathology examination [3], [8], [15]. In contract, other literature reported that SARS-CoV-2 particles may be detected in liver tissue from autopsy of patients with COVID-19 [9]. Patients with underlying liver disease have higher risk of COVID-19 infection and poorer outcome [6]. Cirrhosis has higher risk of developing poorer outcome. As liver injury increases the risk of COVID-19 progression, the utilization of liver function tests may be used as predictor of disease outcome [5].

\section{Management}

The mainstay of COVID-19 management is supportive therapy. Antivirus (oseltamivir, lopinavir, remdesivir, and ritonavir), antibiotic, and antimalarial (chloroquine) are also administered but need further study regarding their efficacy [1]. Most liver damage in COVID-19 patients is mild and transient and may resolve without specific treatment. Supportive measures must be taken to fulfill pulmonary ventilation and prevent cytokine storm. Hepatoprotective drugs may be utilized in patients with pre-existing liver disease and in case of severely injured liver [11], [16], [17]. The development of vaccine is still under ongoing process and should be able in the next 12-18 months. Implementation of health protocol is important to contain the COVID-19 pandemic [24].

\section{Conclusion}

COVID-19 is an emerging pandemic which may cause liver injury. The presence of ACE2 in cholangiocytes and hepatocytes allows direct infection SARS-CoV-2 to liver. Other possible mechanisms are virus-induced cytopathic effects, inflammation process, hypoxiaand shock, increased apoptoticactivity, increased positive end expiratory effect, and drug-induced. Clinical manifestations are usually mild with elevated liver enzymes, bilirubin, and GGT levels. Albumin level may also decrease. Subjects with COVID-19 pre-existing liver injury tend to have deterioration of liver function and increased mortality. The management of liver injury in COVID-19 is supportive. Hepatoprotective drugs may be administered in severely injured liver. 


\section{References}

1. Ge H, Wang X, Yuan X, Xiao G, Wang C, Deng T, et al. The epidemiology and clinical information about COVID-19. Eur J Clin Microbiol Infect Dis. 2020;39(6):1011-9. https://doi. org/10.1007/s10096-020-03874-z

PMid:32291542

2. Bi Q, Wu Y, Mei S, Ye C, Zou X, Zhang Z, et al. Epidemiology and transmission of COVID-19 in 391 cases and 1286 of their close contacts in Shenzhen, China: A retrospective cohort study. Lancet Infect Dis. 2020;20:911-9. https://doi.org/10.1016/ s1473-3099(20)30287-5

3. Musa S. Hepatic and gastrointestinal involvement in coronavirus disease 2019 (COVID-19): What do we know till now? Arab J Gastroenterol. 2020;21(1):3-8. https://doi.org/10.1016/j. ajg.2020.03.002

PMid:32253172

4. Fan Z, Chen L, Li J, Cheng X, Yang J, Tian C, et al. Clinical features of COVID-19-related liver functional abnormality. Clin Gastroenterol Hepatol. 2020;18(7):1561-6.

PMid:32283325

5. Cai Q, Huang D, Yu H, Zhu Z, Xia Z, Su Y, et al. COVID-19: Abnormal liver function tests. J Hepatol. 2020;73(3):566-74. PMid:32298767

6. Ridruejo E, Soza A. The liver in times of COVID-19: What hepatologists should know. Ann Hepatol. 2020;19(4):353-8. https://doi.org/10.1016/j.aohep.2020.05.001

PMid:32425991

7. Cheung KS, Hung IF, Chan PP, Lung K, Tso E, Liu R, et al. Gastrointestinal manifestations of SARS-CoV-2 infection and virus load in fecal samples from the Hong Kong cohort and systematic review and meta-analysis. Gastroenterology. 2020;159(1):81-95. https://doi.org/10.1053/j.gastro.2020.03.065 PMid:32251668

8. Chau T, Lee K, Yao H, Tsang T, Chow T, Yeung Y, et al. SARSassociated viral hepatitis caused by a novel coronavirus: Report of three cases. Hepatology. 2004;39(2):302-10. https://doi. org/10.1002/hep.20111

PMid:14767982

9. Xu L, Liu J, Lu M, Yang D, Zheng X. Liver injury during highly pathogenic human coronavirus infections. Liver Int. 2020;40(5):998-1004. https://doi.org/10.1111/liv.14435 PMid:32170806

10. Huang C, Wang Y, Li X, Ren L, Zhao J, Hu Y, et al. Clinical features of patients infected with 2019 novel coronavirus in Wuhan, China. Lancet. 2020;395(10223):497-506. https://doi. org/10.1016/s0140-6736(20)30183-5

PMid:31986264

11. Feng G, Zheng KI, Yang Q, Rios RS, Targher G, Byrne CD, et al. COVID-19 and liver dysfunction: Current insights and emergent therapeutic strategies. J Clin Transl Hepatol. 2020;8(1):18-24. https://doi.org/10.14218/jcth.2020.00018

PMid:32274342

12. Jin $\mathrm{X}$, Lian J, Hu J, Gao J, Zheng L, Zhang $\mathrm{Y}$, et al. Epidemiological, clinical and virological characteristics of 74 cases of coronavirus-infected disease 2019 (COVID-19) with gastrointestinal symptoms. Gut. 2020;69(6):1002-9. https://doi. org/10.1136/gutjnl-2020-320926 PMid:32213556

13. Zhang $X$. Epidemiology of covid-19. $N$ Engl $J$ Med. 2020;382:1869-70. https://doi.org/10.1056/NEJMc2005157 PMid:32220200

14. World Health Organization. Coronavirus Disease (COVID-19)
Outbreak Situation. Available from: http://www.covid19.who.int. [Last accessed on 2020 May 28].

15. Zhang C, Shi L, Wang F. Liver injury in COVID-19: Management and challenges. Lancet Gastroenterol Hepatol. 2020;5(5):428-30. https://doi.org/10.1016/S2468-1253(20)30057-1 PMid:32145190

16. Mao R, Qiu Y, He J, Tan J, Li X, Liang J, et al. Manifestations and prognosis of gastrointestinal and liver involvement in patients with COVID-19: A systematic review and meta-analysis. Lancet Gastroenterol Hepatol. 2020;5(7):667-78. https://doi. org/10.1016/s2468-1253(20)30126-6

PMid:32405603

17. Boeckmans J, Rodrigues RM, Demuyser T, Pierard D, Vanhaecke T, Rogiers V. COVID-19 and drug-induced liver injury: Aproblem of plenty or a petty point. Arch Toxicol. 2020;94(4):13679. https://doi.org/10.1007/s00204-020-02734-1 PMid:32266419

18. Xiao F, Tang M, Zheng X, Liu Y, Li X, Shan H. Evidence for gastrointestinal infection of SARS-CoV-2. Gastroenterology. 2020;158(6):1831-3. https://doi.org/10.1053/j.gastro.2020.02.055 PMid:32142773

19. Agarwal A, Chen A, Ravindran N, To C, Thuluvath PJ. Gastrointestinal and liver manifestations of COVID-19. J Clin Exp Hepatol. 2020;10:263-5. https://doi.org/10.1016/j.jceh.2020.03.001

20. Gu J, Han B, Wang J. COVID-19: Gastrointestinal manifestations and potential fecal-oral transmission. Gastroenterology. 2020;158(6):1518-9. https://doi.org/10.1053/j.gastro.2020.02.054 PMid:32142785

21. Zhang B, Zhou Z, Qiu Y, Feng F, Feng J, Jia $Y$, et al. Clinical characteristics of 82 death cases with COVID-19. MedRxiv. 2020;2020;15:e0235458. https://doi. org/10.1101/2020/02.26.20028191

22. Huang $Y$, Yang R, Xu Y, Gong P. Clinical characteristics of 36 nonsurvivors with COVID-19 in Wuhan, China. MedRxiv. 2020;(Online ahead of print). https://doi.org/10.1101/2020.02.27.20029009

23. Chen N, Zhou M, Dong $X, Q u ~ J$, Gong F, Han $Y$, et al. Epidemiological and clinical characteristics of 99 cases of 2019 novel coronavirus pneumonia in Wuhan, China: A descriptive study. Lancet. 2020;395(10223):507-13. https://doi.org/10.1016/ s0140-6736(20)30211-7 PMid:32007143

24. Mohamed AA, Mohamed N, Mohamoud S, Zahran FE, Khattab RA, El-Damasy DA, et al. SARS-CoV-2: The path of prevention and control. Infect Disord Drug Targets. 2020;(Online ahead of print). https://doi.org/10.2174/1871526520666200520 112848

\section{PMid:32433010}

25. Sarin SK, Choudhury A, Lau GK, Zheng M, Ji D, Abd-Elsalam S, et al. Pre-existing liver disease is associated with poor outcome in patients with SARS CoV2 infection; The APCOLIS study (APASL COVID-19 liver injury spectrum study). Hepatol Int. 2020;4:1-11. https://doi.org/10.21203/rs.3.rs-36338/v1 PMid:32623632

26. lavarone $M$, D'Ambrosio $R$, Soria A, Triolo M, Pugliese $N$, Poggio PD, et al. High rates of 30-day mortality in patients with cirrhosis and COVID-19. J Hepatol. 2020;(Online ahead of print). https://10.1016/j.jhep.2020.06.001

27. Zhang JC, Wang SB, Xue YD. Fecal specimen diagnosis 2019 novel coronavirus-infected pneumonia. J Med Virol. 2020;92(6):680-2. https://doi.org/10.1002/jmv.25742 PMid:32124995

28. Wang W, Xu Y, Gao R, Lu R, Han K, Wu G, et al. Detection of SARS-CoV-2 in different types of clinical specimens. JAMA. 2020;323(18):1843-4. https://doi.org/10.1001/jama.2020.3786 PMid:32159775 